\title{
Gençler Kategorisindeki Judocuların Antrenör Davranışlarını Değerlendirmesi: Saha Çalışması
}

\author{
Evaluation of Coach Behaviors in the Junior Category Judokas: Case of
}

\author{
Study
}

\author{
ORIJINAL ARAŞTIRMA/ \\ ORIGINAL RESEARCH \\ Şengül DEMİRAL ${ }^{1 \dagger}$ \\ ${ }^{1}$ Trakya Üniversitesi, Edirne \\ https://orcid.org/0000-0001-9771-6846
}

\section{Yayın Bilgisi}

Gönderi Tarihi: 25.06.2019

Kabul Tarihi: 26.09.2019

Online Yayın Tarihi: 31.12.2019

DOI: $10.33459 /$ cbubesbd.581843

\section{$\ddot{O} \mathbf{z}$}

Bu çalışmada cinsiyet, spor yapma yaşı, milli olma veya olmama durumlarına göre gençler kategorisinde yarışan judocular tarafından antrenör davranışları değerlendirilmiştir. Araştırmada nicel araştırma yöntemlerinden betimsel ve ilişkisel tarama tekniği kullanılmıştır. Çalışma grubunu basit tesadüfi örnekleme yöntemi ile seçilen toplam 289 katılımcı (136 kadın/153 erkek) oluşmaktadır. Örneklem grubu, 2019 yılında Gençler Türkiye Judo Şampiyonasında yarışan 1517 yaş sporculardır. Filiz ve Demirhan (2017) tarafından Türkçe geçerlik ve güvenirliği yapılarak, Türkçe 'ye uyarlanan 'Antrenörlük Davranış1 Değerlendirme Ölçeği', orijinal formu "Coaching Behavior Assessment Questionnaire" olan ölçek kullanılmıştır. Türkçe 'ye uyarlanan ölçekte antrenör davranış unsurları ile ilgili 21 ifade yer almaktadır. Ölçekte yer alan her ifade 5'li Likert skalasından puanlanmaktadır. İstatistiksel analizde Kolmogorov-Smirnov, Shapiro Wilk's Mann Whitney U ve Kruskal Wallis-H Testlerinden yararlanılmıştır. Sonuçlar yorumlanırken anlamlılık düzeyi olarak $\mathrm{p}<0,05$ kullanılmıştır. Bulgulara göre; "Cinsiyet, spor yapma yılı, Kaç yıldır spor yapıyorsunuz" değişkenlerine göre "Destek Olma”, "Genel Teşvik Etme”, "Genel Teşvik Öğretim”, "Genel İletişim”, "Hata-Koşullu Teknik Öğretim” değerleri açısından anlamlı bir farklılık bulunmaktadır $(\mathrm{p}<0,05)$. Fakat millilik durumuna göre "Destek olma", "Genel Teşvik öğretim", "Genel iletişim" ve "Hata koşullu teknik öğretim," değerlerinde anlamlı farklılıklar görülmektedir. Özellikle A Millî ve Genç Milli sporcuların diğer millilik grupları arasında antrenör davranışın değerlendirmede anlamlı farklılıklar olduğu görülmektedir. Sonuç olarak bu çalışma ile judo antrenör eğitim programlarının hazırlanması ve mesleki gelişim programlarında dikkat edilmesi gereken unsurların tespitine katkıda bulunacağı düşünülmektedir. Bununla birlikte antrenör davranışlarının incelenmesi ve bu inceleme sonuçlarının değerlendirilmesi başarılı antrenör ya da etkili antrenörlük kavramın geliştirilmesinde önemli bilgiler sunacaktır.

Anahtar Kelimeler: Judo Eğitmeni, Genç Judokas, Ölçme - Değerlendirme.

\begin{abstract}
In this study, coach behaviors were evaluated by judo players competing in the youth category according to gender, age of doing sports, nationality or non-nationality. The study group consisted of 289 participants (136 female / 153 male) selected by simple random sampling method. Participants selected from the 15-17 age group athletes competing in Young Turkey Judo Championship. The validity and reliability of the scale was made by Filiz and Demirhan (2017), and the scale, which was adapted to Turkish, was used as the Coaching Behavior Assessment Questionnaire. The scale includes 21 expressions regarding elements of coach behavior. $\mathrm{p}<0.05$ was used as the level of significance. According to the findings; There is a significant difference in terms of gender, year of doing sports, how many years you have been doing sports, and the values of "Support", "General Incentive", "General Incentive Education", "General Communication", "Error-Conditional Technical Education" $(p<0,05)$. However, there are significant differences in "Support", "General Incentive", "General Incentive Education", "General Communication", "Error-Conditional Technical Education" values according to nationality. In conclusion, it is thought that this study will contribute to the preparation of judo trainer training programs and determination of the elements to be considered in professional development programs. However, examining coach behaviors and evaluating the results of these investigations will provide important information in the development of successful coaching or effective coaching concept.
\end{abstract}

Keywords: Judo Trainer, Junior Judokas, Assessment - Evaluation.

\footnotetext{
+ Sorumlu yazar: Şengül Demiral, judo_edirne22@hotmail.com
} 


\section{GíRiş}

İletişim insanların birbirleri ile olan iliş̧kilerinin temel belirleyicisidir. Literatürde iletişim kavramı genel geçerliliği olan bir tanımlamayı yapmak oldukça güç olmakla birlikte, Püsküllü (1995) "iki kişinin duygu, düşünce ve bilgilerini paylaşarak birbirini anlaması ile ilgili bir süreç" olarak iletişimi tanımlamışıtır. Bir kişinin bir başka kişiye veya takıma herhangi bir etkileşim olmasının ötesinde, bir paylaşma eylemi süreç iletişim olarak ifade edilmektedir. İletişim tek yönlü olmayıp, iki yönlü bir süreç olarak bir yaşamında önemli bir yer tutar ve aynı zamanda spor alanında da önemli bir role sahiptir (Gürgen, 1997). Özellikle sporcu ve antrenör arasındaki etkileşim sporcuların psikolojik, sosyolojik ve fiziksel gelişimleri açısından önemlidir (Jowett ve Ntoumanis, 2003). Olumlu ilişkilerin ve süreçlerin geçtiği ortamda oluşan olumlu bir antrenörsporcu ilişkisi, sporculara becerilerini, motivasyon ve doyumunu artırmakla uygun ortam sağlamaktadır (Altıntaş, Çetinkalp ve Aşçi, 2012).

Antrenör spor dalına özgü, genel ya da ilgili bir biçimde, spor etkinliklerini ve antrenmanlarını uygulatarak; sporcuyu fizyolojik, psikolojik, zihinsel, teknik ve taktiksel olarak hedefe pek performans için eğitim veren kişi olarak tanımlanmaktadır (Sevim, 1998). Antrenör davranış ve mesleki yeterliğinin sporcu üzerine etkisi konusunda birçok araştırma konusu olarak karşımıza çıkmaktadır. Bu etkileşimler sosyal ve sürekli değişen yapıya sahip olması dikkat çekicidir. Bundan dolayı sürekli değişen, karmaşık yapıya sahip olmasından dolayı bu durumun anlaşılması için özel çaba gerektiği görülmektedir (Mallet, 2007). Gelişen ve genişleyen dünyada antrenörlerin mesleki başarısı yetiştirdiği milli takım sporcuları, madalya sayısı, aldığı ödül... vs gibi veriler üzerinden değerlendirilmektedir. Bunun yeterli bir değerlendirme olmadığı ve daha tamamlayıcı bakış açılarına bırakmaya başladığını belirtilmektedir (Mallet ve Cote, 2006).

Chelladurai (1984), Côté, Salmela ve Russell (1995), Smoll ve Smith (1984) tarafindan yapılan çalışmalarda; antrenör ve sporcu arasındaki kompleks ve karmaşık ilişkileri açıklamak için birçok yöntem geliştirildiği ve bu yöntemler temel alınarak yapılan araştırmalarda antrenör davranışlarının sporcunun gelişimini doğrudan etkilediğini gösterdiği belirtilmektedir. Yapılan bu araştırmalarda elde edilen bulgular antrenör, sporcu ve antrenman ortamı arasındaki ilişkiyi göstermiştir. Bununla beraber "Antrenör Davranışlarını Değerlendirme Sistemi” antrenör davranışlarının içeriğini oluşturan; planlama, yardımcı antrenör ile yapılan çalışmalar, fiziksel ve 
zihinsel beceriler gibi boyutları belirleme konularında yetersiz kaldığı belirtilmektedir (Côté, 1998).

Yapılan literatür çalışmalarında Mageau ve Vallerand'ın (2003) geliştirdiği Motivasyon Modeli (Motivational Model) antrenörlük modelinin merkezinde; antrenörün sporcunun veya takımın potansiyelini geliştirmeyi hedefleyen antrenman, organizasyon, yarışma sürecindeki davranışlarının zihinsel modellemesi ile benzer yapıya sahip olduğu görülmektedir (Yapar ve İnce, 2014), Ortaya çıkan farkl11ıklar sonucunda Côté ve arkadaşları (1999) tarafından "Sporcular İçin Antrenör Davranışlarını Değerlendirme Ölçeği (SADDÖ)" [Coaching Behavior Scale for Sports (CBS-S)] geliştirilmiştir. Antrenörlerin müsabaka, yarışma, organizasyonlarda sergiledikleri tutum, davranışlarından ortaya çıkan çıkarımlardan, SADDÖ içerisindeki maddeler oluş̧urulmuş̧ur (Bloom, 1996; Bloom ve ark., 1997; Côté ve ark., 1995; Gilbert ve Trudel, 1997). İyi bir antrenör, sporcunun fiziksel, zihinsel, teknik \& taktik gelişimi destekleyici eğitimden sorumludur. Böylece sporcuların peak performans hedeflerine ulaşabilirler (Becker, 2009).

Antrenörlük Modelinde antrenör ve sporcu bireysel fark değişkenlerini ve antrenörün sporcuların tutum algılarını, farklı değişkenlerin aracılık etkisi kesikli oklarla tanımlanmıştır. Bu nedenle, koçluk davranışlarının nihai etkinliği arabulucu değişkenlerin birçok karmaşık etkileşiminin bir sonucu olduğu belirtilmektedir (Kenow ve Williams, 1992).

Antrenör ve sporcu ilişkisi, beklentileri farklı şekillerde belirlediğini ifa eden birçok çalışmalara rastlamak mümkün. Bunlardan biri Solomon (1998) ve arkadaşlarının yaptığı çalışmada düşüş hedefli sporcular ile yüksek hedefli sporcuların olası farklılıklar üzerine beklentileri sezon boyunca araştırmalar yapıldı. Araştırma soncunda ilerleyen süreç boyunca, yüksek beklentili sporcular, düşük beklentili sporcuların daha fazla geri bildirim aldıkları belirtilmektedir. Günümüzde antrenör ve sporcunun yüksek performans elde edebilmesi için karşılıklı olarak oluşturulan ilişkisinin, ülkemizde özellikle bu çalışmaların (judo sporu) gerektiği kadar yeterli olmaması ve yapılacak çalışmalar sonrasında antrenör sporcu etkileşiminin düzeyleri ile ilgili gerekli bilgilere ulaşabilme isteği bu çalışmaya yol haritası olmuştur. Ayrıca hem gözlem yapılabilme hem de algılanan antrenör davranışlarının her açıdan sporcu performansına etki gücü düşünülürse, antrenör-sporcu ilişkilerinin algılanan davranışlar yönünden incelenmesi başarılı yada etkili antrenörlük için önemli bilgiler sunacaktır. 
Sporda, yüksek seviyede rekabet gerektiren sporlarda ve diğerlerinde bir antrenörün rolünün önemi açıktır. Antrenörün antrene ettiği sporcularının fiziksel, zihinsel, teknik ve taktiksel gelişimlerini desteklemekten ve sporcularının en iyi hedeflerine ulaşmalarını sağlamak iyi bir antrenörün sorumluluğudur (Siekanska, Blecharz ve Wojtowicz., 2013). Bu nedenledir ki bu ç

alışma ile gençler kategorisinde yarışan judocuların 'antrenör davranışlarının seçilen unsurlarını' incelenmesi hedeflenmiştir. Çalışma soncunda, başarılı antrenör ya da etkili antrenörlük kavramın geliştirilmesinde sporcuların önem verdiği kriterler hususunda alana önemli bilgilerin sunulmasına katkı sağlanacaktır.

\section{YÖNTEM}

\section{Araştırma Grubu}

Çalışma örneklemini 2019 Judo Federasyonu Gençler Türkiye Şampiyonasına katılan ve rastgele seçilen toplam 289 sporcudan oluşmaktadır. Katılımcıların n:153'i erkek $(\% 52,9)$, n:136's1 ise $(\% 47,1)$ kadındır.

\section{Veri Toplama Aracı}

Özgün adı "Coaching Behavior Assessment Questionnaire” olan, Filiz ve Demirhan (2017) tarafından Türkçe geçerlik ve güvenirliği yapılarak Türkçeye uyarlanmış olan "Antrenörlük Davranışı Değerlendirme Ölçeği'nin sekiz versiyonundan birisi olan "tercih edilen antrenör davranışlarının sporcu versiyonu" veri toplama aracı olarak kullanılmıştır. Ölçek antrenör davranış unsurları ile ilgili (destek olma, destek olmayı kısıtlama, hata-koşullu teşvik etme, hata-koşullu teknik öğretim, ceza, cezalandırıcı teknik öğretim, hataları dikkate almama, denetimde tutma, genel teşvik öğretim, genel teşvik etme, organizasyon ve genel iletişim kurma) 48 ifade yer almaktadır. Antrenör davranışlarının seçilen unsurlarını ölçmek için ifadeler 12 kategoriye (faktör) ayrılmıştır ve her kategori dört madde ile ifade edilmektedir. Ölçekte yer alan her ifade "Hiçbir Zaman (1)" ile "Her Zaman (5)" olmak üzere 5'li Likert skalasında puanlanmaktadır. Ölçekte ters puanlanan ifade yoktur. Ölçekten en düşük 48 puan, en yüksek 240 puan alınmaktadır. 


\section{Verilerin Analizi}

$\mathrm{Bu}$ çalışmada elde edilen veriler SPSS 17 paket programı ile analiz edilmiştir. Değişkenlerin normal dağılımdan gelme durumları araştırılırken Kolmogorov-Smirnov ve Shapiro Wilk's testlerinden yararlanılmıştır. Sonuçlar yorumlanırken anlamlılık düzeyi olarak 0,05 kullanılmış olup; $\mathrm{p}<0,05$ olması durumunda değişkenlerin normal dağılıma uyum göstermediği, p >0,05 olması durumunda ise değişkenlerin normal dağılıma uyum gösterdikleri belirtilmiştir. Gruplar arasındaki farklılıklar incelenirken değişkenlerin normal dağılıma uyum göstermedikleri durumlarda parametrik olmayan (nonparametric) Mann Whitney U ve Kruskal Wallis-H Testlerinden yararlanılmıştır. Kruskal Wallis-H Testinde anlamlı farklılıkların görülmesi durumunda Post-Hoc Çoklu Karşılaştırma Testi ile aralarında farklılık olan gruplar belirlenmiştir. Sonuçlar yorumlanırken anlamlılık düzeyi olarak 0,05 kullanılmış olup; $p<0,05$ olması durumunda anlamlı bir farklılığın olduğu, $\mathrm{p}>0,05$ olması durumunda ise anlamlı bir farklılığın olmadığ 1 belirtilmiştir.

\section{BULGULAR}

Tablo 1. Kategorik değişkenlere ilişkin frekans ve dağılım tablosu

\begin{tabular}{|c|c|c|c|}
\hline & & $\mathrm{n}$ & $\%$ \\
\hline \multirow{2}{*}{ Cinsiyet } & Erkek & 153 & 52,9 \\
\hline & Kadın & 136 & 47,1 \\
\hline \multirow{7}{*}{ Kaç yıldır spor yapıyorsunuz? } & 1-3 Y11 & 11 & 3,8 \\
\hline & 3-5 Yil & 53 & 18,3 \\
\hline & 5-7 Yil & 89 & 30,8 \\
\hline & 7-8 Yil & 54 & 18,7 \\
\hline & 8-9 Y1l & 40 & 13,8 \\
\hline & 9-10 Yil & 28 & 9,7 \\
\hline & 10 Yil ve üstü & 14 & 4,9 \\
\hline \multirow{6}{*}{ Millilik Durumu } & Milli Değil & 150 & 51,9 \\
\hline & A Milli & 4 & 1,4 \\
\hline & Genç Milli & 33 & 11,4 \\
\hline & Yıldız Milli & 46 & 15,9 \\
\hline & Küçük Milli & 8 & 2,8 \\
\hline & Ümit Milli & 48 & 16,6 \\
\hline
\end{tabular}

Tablo 1'de katılımcıların yani 'Gençler Türkiye Şampiyonası'na katılan katılımcıların \%52,9'u erkek, \%47,1'i kadındır. Bu katılımcıların \%30,8'i 5-7 yıldır spor yaptığı ve katılımcıların \%51,9’u milli olmadığı, A Milli olan katılımcıların oranı ise sadece \%1,4 olduğu görülmektedir. 
Demiral, Ş. (2019). Gençler Kategorisindeki Judocuların Antrenör Davranışlarını Değerlendirmesi; Saha Çalışması, CBÜ Beden Ĕ̈itimi ve Spor Bilimleri Dergisi, 14 (2), 249-262.

Tablo 2. Sayısal değişkenlere ilişkin frekans ve dağılım tablosu

\begin{tabular}{lccrrr}
\hline & n & Ort. & ss. & Min & Max \\
\hline Destek Olma & 289 & 24,24 & 4,47 & 10 & 30 \\
Genel Teşvik Etme & 289 & 19,03 & 3,91 & 5 & 25 \\
Genel Teşvik Öğretim & 289 & 12,10 & 3,82 & 3 & 61 \\
Genel İletişim & 289 & 14,44 & 3,25 & 4 & 20 \\
Hata-Koşullu Teknik Öğretim & 289 & 11,25 & 2,72 & 3 & 15 \\
\hline
\end{tabular}

Tablo 2'de destek olma değerleri 10-30 aralığında değişmekte olup, ortalaması 24,24'tür. Genel teşvik etme değerleri 5-25 aralığında değişmekte olup, ortalaması 19,03 olduğu, Genel teşvik öğretim değerleri 3-61 aralığında değişmekte olup, ortalaması 12,10 olduğu, Genel iletişim değerleri 4-20 aralığında değişmekte olup, ortalaması 14,44 olduğu, Hata-koşullu teknik öğretim değerleri 3-15 aralığında değişmekte olup, ortalamasının 11,25 olduğu görülmektedir.

Tablo 3. "Cinsiyet" değişkenine göre ortalamaların karşılaştırılması

\begin{tabular}{lcrrrrrrr}
\hline & Cinsiyet & $\mathrm{n}$ & Ort. & ss. & Min & Max & $\mathrm{Z}$ & $\mathrm{p}$ \\
\hline \multirow{2}{*}{ Destek Olma } & Erkek & 153 & 24,21 & 4,44 & 10 & 30 & $-0,155$ & 0,877 \\
& Kadın & 136 & 24,28 & 4,52 & 10 & 30 & \\
Genel Teşvik Etme & Erkek & 153 & 19,03 & 3,82 & 9 & 25 & $-0,146$ & 0,884 \\
& Kadın & 136 & 19,03 & 4,02 & 5 & 25 & & \\
Genel Teşvik Öğretim & Erkek & 153 & 11,93 & 2,30 & 6 & 15 & $-0,789$ & 0,431 \\
\multirow{2}{*}{ Genel İletişim } & Kadın & 136 & 12,28 & 5,01 & 3 & 61 & & \\
\multirow{2}{*}{ Hata-Koşullu Teknik Öğretim } & Erkek & 153 & 14,34 & 3,15 & 6 & 20 & $-0,625$ & 0,532 \\
& Kadın & 136 & 14,55 & 3,36 & 4 & 20 & & \\
& Erkek & 153 & 11,44 & 2,60 & 3 & 15 & $-1,137$ & 0,256 \\
\hline
\end{tabular}

Tablo 3'de görüldüğü gibi “Cinsiyet değişkenine göre, destek olma, genel teşvik etme, genel teşvik öğretim, genel iletişim, hata- koşullu teknik öğretim değişkenleri arasında istatistiksel olarak anlamlı farklılık bulunmamaktadır $(\mathrm{p}>0.05)$ 
Demiral, Ş. (2019). Gençler Kategorisindeki Judocuların Antrenör Davranışlarını Değerlendirmesi; Saha Çalışması, CBÜ Beden Ĕ̈itimi ve Spor Bilimleri Dergisi, 14 (2), 249-262.

Tablo 4. Judocuların spor yapma yılına göre ortalamaların karşılaştırılması

\begin{tabular}{|c|c|c|c|c|c|c|c|c|c|}
\hline & $\begin{array}{l}\text { Kaç yıldır spor } \\
\text { yapıyorsunuz? }\end{array}$ & $\mathrm{n}$ & Ort. & ss. & Min & Max & Kikare & $\mathrm{p}$ & Fark \\
\hline \multirow{7}{*}{ Destek Olma } & 1-3 Yil & 11 & 22,64 & 1,91 & 19 & 25 & \multirow{7}{*}{7,849} & \multirow{7}{*}{0,249} & \multirow{7}{*}{-} \\
\hline & 3-5 Y11 & 53 & 24,72 & 4,26 & 10 & 30 & & & \\
\hline & 5-7 Yil & 89 & 24,47 & 4,29 & 12 & 30 & & & \\
\hline & 7-8 Y 11 & 54 & 23,67 & 4,30 & 11 & 30 & & & \\
\hline & 8-9 Y 11 & 40 & 24,83 & 4,62 & 12 & 30 & & & \\
\hline & 9-10 Y11 & 28 & 23,54 & 5,40 & 12 & 30 & & & \\
\hline & 10 Yil ve üstü & 14 & 24,21 & 5,96 & 10 & 30 & & & \\
\hline \multirow{7}{*}{ Genel Teşvik Etme } & $1-3 Y_{11}$ & 11 & 15,91 & 3,51 & 10 & 22 & \multirow{7}{*}{13,949} & \multirow{7}{*}{$0,030 *$} & \multirow{7}{*}{$\begin{array}{l}1-2 \\
1-3 \\
1-4 \\
1-5\end{array}$} \\
\hline & 3-5 Y 11 & 53 & 19,89 & 3,59 & 10 & 25 & & & \\
\hline & 5-7 Yil & 89 & 18,84 & 4,15 & 9 & 25 & & & \\
\hline & 7-8 Y1l & 54 & 19,30 & 3,47 & 11 & 24 & & & \\
\hline & 8-9 Yil & 40 & 19,98 & 2,97 & 11 & 25 & & & \\
\hline & $9-10 Y_{11}$ & 28 & 17,86 & 4,18 & 9 & 25 & & & \\
\hline & 10 Y1l ve üstü & 14 & 18,00 & 5,48 & 5 & 24 & & & \\
\hline \multirow{14}{*}{ Genel Teşvik Öğretim } & $1-3$ Y1l & 11 & 11,64 & 1,29 & 10 & 15 & \multirow{14}{*}{6,178} & \multirow{14}{*}{0,403} & \multirow{14}{*}{-} \\
\hline & 3-5 Yil & 53 & 12,47 & 1,80 & 8 & 15 & & & \\
\hline & 5-7 Y1l & 89 & 11,87 & 2,25 & 6 & 15 & & & \\
\hline & 7-8 Yil & 54 & 11,61 & 2,78 & 5 & 15 & & & \\
\hline & 8-9 Y1l & 40 & 13,63 & 8,10 & 6 & 61 & & & \\
\hline & $9-10 Y_{11}$ & 28 & 11,43 & 3,33 & 6 & 15 & & & \\
\hline & 10 Yil ve üstü & 14 & 11,36 & 3,56 & 3 & 15 & & & \\
\hline & $1-3 Y_{11}$ & 11 & 13,27 & 2,76 & 9 & 18 & & & \\
\hline & 3-5 Yil & 53 & 14,47 & 3,18 & 8 & 20 & & & \\
\hline & 5-7 Y1l & 89 & 14,06 & 3,37 & 5 & 20 & & & \\
\hline & 7-8 Yil & 54 & 14,43 & 3,31 & 6 & 20 & & & \\
\hline & 8-9 Y1l & 40 & 15,63 & 2,70 & 10 & 20 & & & \\
\hline & $9-10 Y_{11}$ & 28 & 15,04 & 3,02 & 7 & 20 & & & \\
\hline & 10 Yil ve üstü & 14 & 13,14 & 3,98 & 4 & 20 & & & \\
\hline
\end{tabular}

Tablo 4. Judocuların spor yapma yılına göre ortalamaların karşılaştırılması

\begin{tabular}{|c|c|c|c|c|c|c|c|c|c|}
\hline & $\begin{array}{l}\text { Kaç yıldır spor } \\
\text { yapıyorsunuz? }\end{array}$ & $\mathrm{n}$ & Ortalama & ss. & Min & Max & Kikare & $\mathrm{p}$ & Fark \\
\hline \multirow{7}{*}{ Hata-Koşullu Teknik Öğretim } & $1-3$ Y1l & 11 & 10,55 & 2,42 & 6 & 13 & \multirow{7}{*}{5,418} & \multirow{7}{*}{0,491} & \multirow{7}{*}{-} \\
\hline & 3-5 Y1l & 53 & 10,98 & 2,76 & 3 & 15 & & & \\
\hline & 5-7 Yil & 89 & 11,30 & 2,77 & 5 & 15 & & & \\
\hline & 7-8 Y1l & 54 & 10,89 & 2,96 & 5 & 15 & & & \\
\hline & 8-9 Y1l & 40 & 11,90 & 2,31 & 6 & 15 & & & \\
\hline & $9-10 \mathrm{Y}_{11}$ & 28 & 11,75 & 2,70 & 5 & 15 & & & \\
\hline & 10 Yil ve üstü & 14 & 11,07 & 2,70 & 7 & 15 & & & \\
\hline
\end{tabular}

Tablo 4'de ifade edildiği gibi "Kaç yıldır spor yapıyorsunuz" değişkenine göre destek olma, genel teşvik öğretim, genel iletişim, hata-koşullu teknik öğretim, değişkenleri arasında istatistiksel olarak anlamlı bir farklılık bulunmamaktadır $(p>0,05)$, genel teşvik etme değerleri açısından ise istatistiksel olarak anlamlı bir farklılık bulunmaktadır $(\mathrm{p}<0,05)$. 
Demiral, Ş. (2019). Gençler Kategorisindeki Judocuların Antrenör Davranışlarını Değerlendirmesi; Saha Çalışması, CBÜ Beden Ĕ̈itimi ve Spor Bilimleri Dergisi, 14 (2), 249-262.

Tablo 5. Judocuların milli olma durumlarına göre ortalamaların karşılaştırılması

\begin{tabular}{|c|c|c|c|c|c|c|c|c|c|}
\hline & Millilik Durumu & $\mathrm{n}$ & Ortalama & ss. & Min & $\operatorname{Max}$ & Kikare & $\mathrm{p}$ & Fark \\
\hline \multirow{6}{*}{ Destek Olma } & Milli Değil & 150 & 24,14 & 4,01 & 14 & 30 & \multirow{6}{*}{20,892} & \multirow{6}{*}{$0,001 *$} & \\
\hline & A Milli & 4 & 28,50 & 1,29 & 27 & 30 & & & $2-1,2-3$ \\
\hline & Genç Milli & 33 & 25,97 & 4,17 & 10 & 30 & & & $2-4,2-5$ \\
\hline & Yıldız Milli & 46 & 22,54 & 5,18 & 11 & 30 & & & $2-6,3-4$ \\
\hline & Küçük Milli & 8 & 23,50 & 1,60 & 21 & 25 & & & 3-5 \\
\hline & Ümit Milli & 48 & 24,77 & 5,15 & 10 & 30 & & & \\
\hline \multirow{6}{*}{ Genel Teşvik Etme } & Milli Değil & 150 & 18,84 & 3,88 & 9 & 25 & \multirow{6}{*}{6,955} & \multirow{6}{*}{0,224} & \\
\hline & A Milli & 4 & 21,50 & 2,38 & 18 & 23 & & & \\
\hline & Genç Milli & 33 & 18,24 & 4,51 & 5 & 25 & & & \\
\hline & Yıldız Milli & 46 & 19,09 & 3,46 & 13 & 24 & & & - \\
\hline & Küçük Milli & 8 & 18,63 & 3,54 & 13 & 22 & & & \\
\hline & Ümit Milli & 48 & 19,96 & 4,04 & 9 & 25 & & & \\
\hline \multirow{6}{*}{ Genel Teşvik Öğretim } & Milli Değil & 150 & 12,43 & 4,50 & 6 & 61 & \multirow{6}{*}{13,424} & \multirow{6}{*}{$0,020 *$} & \\
\hline & A Milli & 4 & 12,00 & 3,83 & 7 & 15 & & & $1-4,1-5$ \\
\hline & Genç Milli & 33 & 12,30 & 2,91 & 3 & 15 & & & $2-4,2-5$ \\
\hline & Yıldız Milli & 46 & 10,98 & 2,89 & 5 & 15 & & & $3-4,3-5$ \\
\hline & Küçük Milli & 8 & 10,63 & 1,19 & 9 & 12 & & & $6-4,6-5$ \\
\hline & Ümit Milli & 48 & 12,23 & 2,86 & 6 & 15 & & & \\
\hline \multirow{6}{*}{ Genel İletişim } & Milli Değil & 150 & 14,19 & 3,31 & 5 & 20 & \multirow{6}{*}{23,527} & \multirow{6}{*}{$0,001 *$} & \\
\hline & A Milli & 4 & 18,75 & 1,26 & 17 & 20 & & & $2-1,2-3$ \\
\hline & Genç Milli & 33 & 14,39 & 3,37 & 4 & 20 & & & $2-4,2-5$ \\
\hline & Yıldız Milli & 46 & 14,28 & 3,20 & 6 & 20 & & & $2-6,5-1$ \\
\hline & Küçük Milli & 8 & 11,13 & 1,81 & 9 & 14 & & & $\begin{array}{l}5-3,5-4 \\
5-6\end{array}$ \\
\hline & Ümit Milli & 48 & 15,60 & 2,60 & 10 & 20 & & & \\
\hline \multirow{6}{*}{$\begin{array}{l}\text { Hata-Koşullu Teknik } \\
\text { Öğretim }\end{array}$} & Milli Değil & 150 & 11,04 & 2,71 & 5 & 15 & \multirow{6}{*}{20,95} & \multirow{6}{*}{0,001 * } & \\
\hline & A Milli & 4 & 13,50 & 1,29 & 12 & 15 & & & $2-1,2-3$ \\
\hline & Genç Milli & 33 & 11,88 & 2,52 & 6 & 15 & & & $2-4,2-5$ \\
\hline & Yıldız Milli & 46 & 10,93 & 2,65 & 5 & 15 & & & $2-6,5-1$ \\
\hline & Küçük Milli & 8 & 8,13 & 2,47 & 6 & 11 & & & $5-3,5-4$ \\
\hline & Ümit Milli & 48 & 12,13 & 2,56 & 3 & 15 & & & $5-6$ \\
\hline
\end{tabular}

Tablo 5'de "Millilik Durumu” değişkenine göre, “destek olma, genel teşvik öğretim, genel

iletişim, hata-koşullu teknik öğretim değişkenleri arasında istatistiksel olarak anlamlı bir farklılık bulunmaktadır $(p<0,01)$. "Millilik Durumu" değişkenine göre, genel teşvik etme değerleri açısından istatistiksel olarak anlamlı bir farklılık bulunmamaktadır ( $\mathrm{p}>0,05)$.

\section{TARTIŞMA}

Antrenör davranışlarının değerlendirmesinde kültür farklılıkların etkileri görülmektedir. Antrenör davranışları hem spor sistemlerinden hem de ülkeler ve spordaki kültürlerden etkilendiği literatürde çalışmalarda belirtilmektedir. Örneğin İsveç ve Kuzey Amerika spor gelenekleri, okulla bağlantılı spor organizasyonlarına verilen önemle, Kuzey Amerika geleneğinde gönüllü bağlılık odaklı İsveç geleneği ile büyük ölçüde farklılık göstermektedir (Cushion, 2010) ve daha çok işbirliği ilişki odaklı davranışları kullanma eğiliminde oldukları görülmektedir (Northouse, 2013). Antrenör davranışlarını değerlendirme ölçeğine paralel olarak, Carlston ve Lundqvist (2015) sporcular tarafından antrenör değerlendirme ölçeğini İsveç kültürün de uyarlamasını çalışılırken, Koh, Kawabata ve Mallet (2014) Singapur kültürüne uyarlama çalışmalarını yapmıştırlar. Carlston 
ve Lundqvist araştırmalarında; teknik beceri, zihinsel hazırlık ve yarışma stratejisi konularında ölçeğin güçlü olduğunu belirtmişlerdir. Koh, Kawabata ve Mallet'in bulgularının da Singapur örneklemi için 7 boyutlu ölçeğin özgün formu ile tutarlı bir yapıda olduğunu göstermiştir.

Antrenör davranışlarının değerlendirilmesi ve sporcular tarafından antrenörlerin değerlendirilmesi ölçekleri her yönüyle sporcu ve antrenör ilişkilerinin derinlemesine incelemeye çalışılan sadece birkaç ölçekten biridir. Antrenör ve sporcu ilişkisini incelenmeye devam edildiğinde konu ile ilgili literatür taraması sonucunda Coykendal (2014) sporcuların tercih ettikleri ve beklenen antrenörlük davranışları ve antrenörlerin bu davranışları karşılayıp karşılamadığı konusunu incelediği görülmektedir. Çalışmada antrenörlerin beklenen ve tercih edilen davranışlarını yerine getirip getirmediğini incelediği çalışmada; bireysel spor ve takım sporu sporcuları incelenmiştir. Sporcuların karar almada yer alan, gelişim becerileri üzerine yoğunlaşan, olumlu bir antrenör-sporcu ilişkisi geliştiren ve tüm kararları kendi başına vermeyen antrenörleri tercih ettikleri ortaya koydu. Ayrıca kadınlar ve erkekler arasındaki beklenti ve tercihler, spor türü ve spor yapma yılı arasında anlamlı bir fark olmadığını da ortaya koyduğu görülmektedir. Bu verilerin tablo 3'de elde edilen bulguları desteklediği görülmektedir.

Antrenör davranışlarının değerlendirilmesinin dışsal motivasyon etkisini etkileyen farklı çalışmalara rastlanmaktadır. Bu çalışmalardan biri olan bu araştırmada erkeklerde kadın sporculardan daha yüksek düzeyde dışsal motivasyon olduğunu göstermiştir (Monazami, Hedayatikatooli, Neshati ve Beiki, 2012). Ayrıca antrenör sporcu etkileşimlerinin duygusal tarafı ile kesinlikle sınırlı davranışlar, erkekler tarafından erkeklerden daha büyük oranda takdir edildiği belirtilmektedir. Aynı zamanda erkek sporcuların geri bildirim ve teknik talimatlara daha fazla değer verirken, kadınlar sporcular ise duygulara yönelik eylemlere daha fazla ihtiyaç duymuş ve antrenörüne güçlü bir inanca sahip olduğu belirtmişlerdir (Miller, Ogilvie ve Branch, 2008). Bu bilgiler tablo 5'deki bulguları destekleyici niteliktedir. Çünkü millilik durumları yıllara göre değiştiğinden dolayı, ümitlerden büyüklere kadar olan millilik durumlarının, geçen yıllara bağlı olarak antrenör sporcu ilişkilerini etkilediği görülmektedir.

Başka bir çalışmada, burslu yüzme sporcularının kontrolcü antrenör davranışlarının algılanan kontrol koçluğu arasındaki önemli etkileşim algılanan yetkinliği öngören davranışlar belli ölçüde desteklediği belirtilmektedir. Spesifik olarak, antrenörlerin daha az kontrol edici olarak algılayan sporcular, burs durumu ile algılanan yeterlilik arasında olumlu bir ilişki olduğunu 
belirtilmektedir. Sporculardan çok daha fazla denetleyici olarak algılayanların böyle bir ilişki göstermedikleri belirtilmektedir (Matosic, Cox, ve Amorose, 2013). Burada burs durumu ile algılanan yeterlilik arasında olumlu bir ilişki ile Tablo 5'de verilen, Hatta-koşullu teknik öğretim değişkenini destekleyici niteliktedir.

Literatürde liderlik ve antrenör davranışları üzerine yapılan çalışmalardan biri olan ve Smoll ve Smith'in (1984) üzerinde çalıştığı bu araştırmada ise spordaki liderlik davranışları modeli, bir sporcunun antrenör davranışlarına verdiği tepkiyi yönlendirecek bilişsel ve duyuşsal süreçleri incelemek için bir çerçeve sunduğunu belirtmektedirler. Yani antrenörün liderlik özellikleri sergilediği davranışları etkilediği ve bu davranışların değerlendirilmesinde liderlik özelliklerinin incelenmesinin önemi belirtmektedir. Çalışmada liderlik özelliğinin antrenör sporcu ilişkilerinde 'genel teşvik etme ve genel teşvik öğretim' değişkenini etkilediği düşünülmektedir.

Antrenör davranışlarının bireysel ve takım sporları üzerinden inceleyen bu araştırma; bireysel ve takım sporlarındaki sporcuların antrenör davranış algıları arasındaki farklılıkları ortaya koymaktadır. Bireysel sporcular antrenör ve eğitime, sosyal desteğe ve antrenörlerden gelen olumlu geribildirim, lideri davranışlarına yüksek puanlar verdiği, olumsuz antrenörlük davranışına daha az puanlama verdiği çalışmada belirtilmektedir (Velikovic, Djurovic, Dimic, Mujanovic ve Markovic, 2016). Antrenör davranışlarını inceleyen Uzun, Çon, Taşmektepligil ve İmamoğlu (2017); olumsuz antrenör davranışlarında, kadın sporcuların erkek sporculardan çok daha yüksek puan ortalamasına sahip olduğunu belirlenmiştirler. Buna göre kadın sporcuların erkek sporculara göre antrenörlerinin olumsuz davranışlarından daha fazla etkilendiği söylenebilir. Antrenörlerin kadın sporcularda algılanan olumsuz algıyı azaltmak için aralıklı olarak kişilik gelişim seminerlerine katılmaları önerildiği araştırmada görülmektedir (Uzun ve ark., 2017). Çalışmada cinsiyetin antrenör ve sporcu ilişkileri üzerinde anlamlı bir farklılık olmamasından dolayı bu çalışma ile farklılık göstermektedir. Başka bir çalışmada ise antrenörlerin sporcularıyla yüksek kaliteli ilişkiler kurmasını ve sporcuların ilişkisinin sporcuların geneline etkisinin ortaya çıkmasına izin veren psikolojik faktörler hakkında fikir verildiği çalışmalar yapıldığı görülmektedir (Lafrenière, Jowett, Vallerand ve Carbonneau, 2011). Bu nedenle Filiz ve Demirhan'in (2017) Türkçeye uyarladığı ölçeğin güncellenerek, psikolojik faktörlerinde değerlendirmeye alınması, antrenör ve sporcu ilişkilerinin değerlendirilmesine daha kapsamlı 1şık tutacağı düşünülmektedir. Spor eğitim-öğretiminde antrenör davranışlarının araştıılması (Judo modeli) konulu çalışmada, 
antrenörlerin eğitim düzeyleri, gelir dağılımı ve cinsiyet değişkenine göre anlamlı farklılıklar gözlenmiş̧; antrenör kültür etkileşimi tespit edildiği görülmektedir (Kavlu, 2002). Antrenörlerin davranışlarının değerlendirilmesinde kurumsal yaklaşımların etkisini incelenen birkaç araştırmada; sporcuların hedeflerine ulaşma başarılarında, kolektif yeterlik takım ve bireyin performansına önemli etki gücünden dolayı, antrenörlerin davranışları, hedef yönelimleri, motivasyonel iklim, zaman içinde farklılık da gösterebildiği literatürde görülmektedir. Sporcuların algıları bu farkların bir süreç boyunca nasıl bir ilişki gösterdiğini incelenmesi, bu oluşumları ve gelişimini içeren etmenleri tanımlamak için kuramsal yaklaşımlara ihtiyaç vardır. Sporcuların algıladıkları antrenörlük davranışı (Chelladurai ve Saleh, 1978, Chelladuria, 1984), algılanan motivasyonel iklim (Walling, Duda ve Chi, 1993), hedef yönelimleri (Duda ve Nicholls, 1992) gibi kuramsal yaklaşımlarda üzerinde durulduğu da görülmektedir (Toros, 2010).

\section{SONUÇ}

Sonuç olarak; “Antrenörlük Davranışı Değerlendirme Ölçeği’nin sekiz versiyonundan birisi olan tercih edilen antrenör davranışlarının sporcu versiyonu" nu Türkçeye uyarlama ölçeğine göre gençler kategorisinde yarışan kadın \& erkek judokaların (judo yapan sporcu) tercih ettikleri antrenör davranışlarında; Cinsiyet değişkenine göre anlamlı farklılık olmadı̆̆ı, “'Kaç Yıldır Spor Yapıyorsunuz ?’ Değiş̧enine Göre Ortalama 'Genel Teşvik Etme' Anlamlı Farklılık Olduğu Ve “Millilik Durumu” Değişkenine Göre Ortalama “Destek Olma”, “Genel Teşvik Öğretim”, “Hata-Koşullu Teknik Öğretim” de anlamlı farklılık olduğu görülmektedir. Bu veriler sporcuların tercih ettikleri antrenör davranışlarında belirlenmesi için bir belirteç olarak kullanılması amaçlanmıştır. Ayrıca antrenörler hakkında gelişen veri tabanını genişletmeyi amaçlayan hem teorik hem de uygulamalı araştırmalara katkıda bulunacağı düşünülmektedir. Antrenörlerin davranışları hakkında geri bildirim almalarına olanak tanıdığı için çoğu zaman zor olan antrenör gelişimi üzerine daha fazla araştırma yapılmasına katkı sağlayacağı düşünülmektedir.

Burada belirtilen tüm başlıklar çalışmada kullanılan ölçek ile ilişkilendirilerek yeni bir çalışma ile üzerinde çalışılması, antrenör sporcu ilişkilerinin tanımlanmasına katkı sağlayacaktır. 


\section{TEŞEKKÜR}

\section{Anketlerin uygulanmasında katkılarından dolayı Türkiye Judo Federasyonu Başkanı Sezer HUYSUZ'a ve ölçeği kullanmama izin veren Bijen FíLiZ'e teşekkür ederim.}

\section{KAYNAKLAR}

Altıntaş, A., Çetinkalp, Z. K., \& Aş̧̧i, F. H. (2012). Antrenör-sporcu ilişkisinin değerlendirilmesi: Geçerlik ve güvenirlik çalışması. Spor Bilimleri Dergisi, 23(3), 119-128.

Bloom GA, Durant Bush, N. \& Salmela J.H. (1997). Pre and post- competition routine of expert coaches of team sports. The Sport Psychologist, 11(2), 127-141.

Bloom, G.A. (1996). Competition: Preparing for and operating in competition. In J. H. Salmela (Ed.) Great Job Coach (pp.139178). Ottawa: Potentium.

Carlsson A. \& Lundqvist C. (2015). The coaching behavior scale for sport (CBSS): A psychometric evaluation of the Swedish version. Scandinavian Journal of Medicine and Science in Sports 26(1), 116-123.

Chelladurai P. (1984). Leadership in Sport. In J.M. Silva, R.S. Weinberg (Eds.) Psychological Foundations of Sport, s. $329-339$ Champaign, IL; Human Kinetics.,

Chelladurai, P. \& Saleh, S. (1978). Preferred leadership in sports. Canadian Journal of Applied Sport Sciences, 3, 85-92.

Côté, J., Salmela J.H. \& Russell, S.J. (1995). The knowledge of high performance gynastic coaches: Competetion and training considerations. The Sport Psychologist, 9, 76-95.

Côté, J. (1998). Coaching research and intervention. Anintroduction to the special issue Avante, 4(3),1-15

Côté, J., Yardley, J., Hay, J., Sedgwick, W., \& Baker, J. (1999). An exploratory examination of the coaching behaviour scale for sport. Avante, 5, 82-92.

Coykendall, T. (2014). Player Preferences for Coaching Behaviors, Sport Management Undergraduate. Paper 52.

Cushion, C. (2010). Sport coaching: professionalisation and practice. Oxford: Elsevier, 63-83.

Duda, J.L. \& Nicholls, J. (1992). Dimensions of achievement motivation in schoolwork and sport. Journal of Educational Psychology, 89, 290-299.

Filiz. B., \& Demirhan, G. (2017). Antrenörlerin davranışı değerlendirme ölçeği’nin Türk kültürüne uyarlanması. Spormetre, 15(1), $1-10$

Gilbert, W. \& Trudel, P. (1997) A case study of elite team sport coaching. Paper presented at the meeting of the Asociation for the dvancement of applied Sport Psychology. San Diego, USA.

Gürgen, H. (1997). Örgütlerde İletişim Kalitesi. İstanbul: Der Yayınları, s. 9-10.

Jowett, S. \& Ntoumanis, N. (2003). The Greek coach- athlete relationship questionnaire (Grcart-Q): Scale construction and validation. International Journal of Sport Psychology, 34, 101-124

Kavlu, M. (2002). Spor eğitim-öğretiminde antrenör davranışlarının araştırılması (Judo modeli). Yayınlanmış doktora tezi, Marmara Üniversitesi SBE. 
Demiral, Ş. (2019). Gençler Kategorisindeki Judocuların Antrenör Davranışlarını Değerlendirmesi; Saha Çalışması, CBÜ Beden Ĕ̈itimi ve Spor Bilimleri Dergisi, 14 (2), 249-262.

Kenow, L. J. \& Williams, J.M. (1992). Relationship between anxiety, self-confidence and evaluation of coaching behaviors. Faculty Publications. Published Version. Submission. http://digitalcommons.linfield.edu/hhpafac_pubs/2.

Kenow, L. \& Williams, J.M. (1999). Coach-athlete compatibility and athlete's perception of coaching behaviors. Journal of Sport Behavior, 22(2), 251-259.

Kenow, L.J. \& Williams, J.M. (1992). Relationship between anxiety, self-confidence, and evaluation of coaching behaviors. The Sport Psychologist, 6(4), 344-35.

Koh, K.T, Kawabata, M. \& Mallett, C.J. (2014). The coaching behavior scale for sport: factor structure examination for singaporean youth athletes. International Journal of Sports Science and Coaching, 9(6), 1311-1324.

Lafrenière, M.K., Jowett, S., Vallerand, R.J. \& Carbonneau, N. (2011). Passion for coaching and the quality of the coach athlete relationship: The mediating role of coaching behaviors, Psychology of Sport and Exercise, 12 -144-152.

Mageau, G.A., Vallerand, R.J. (2003) The coach-athlete relationship: A motivational model. Journal of Sports Sciences 21(11), 883-904.

Mallett, C.J. (2007). Modelling the Complexity of the coaching process: A Commentary. International Journal of Sport Science and Coaching, 2(4), 407-409

Mallett, C. \& Côté, J. (2006). Beyond winning and losing: Guidelines for evaluating high performance coaches. The Sport Psychologist, 20, 213-218

Matosic, D., Cox, A.E. \& Amorose, A.J. (2013). Scholarship status, controlling coaching behavior and intrinsic motivation in collegiate swimmers: A test of cognitive evaluation theory. Sport, Exercise, and Performance Psychology, Vol. 3(1), 112 .

Miller, T.W., Ogilvie, B.C. \& Branch, J. (2008). Sport psychology consultation: The influence of gender on learning style. Consulting Psychology Journal: Practice and Research, 60(3), 279-285.

Monazami, M., Hedayatikatooli, A., Neshati, A. \& Beiki, Y. A. (2012). Comparison of the motivation of male and female competitive athletes in Golestan, Iran. Annals of Biological Research, 3(1), 31-35.

Northouse, P.G. (2013). Leadership: theory and practice, 6th edn. Thousand Oaks: Sage Publication, 2013: $383-422$.

Püsküllüoğlu, A. (1995). Türkçe Sözlük. İstanbul: Yapı Kredi Yayınları Ltd Şti. s. 1529.

Sevim, Y. (1998). Türkiye'de antrenör eğitim yapısı ve temel ilkeleri. Gazi Beden Eğitimi ve Spor Bilimleri Dergisi, 3 (1), 1-10. Retrieved from http://dergipark.org.tr/gbesbd/issue/27955/305047

Siekanska, M., Blecharz, J., \& Wojtowicz, A. (2013). The athlete's perception of coaches' behavior towards competitors with a different sports level. Journal of Human Kinetics, volume 39, 231-242 DOI: 10.2478/hukin-2013-0086

Smoll, F.L. \& Smith R.E. (1984). Leadership research in youth sports. In J. M. Silva III \& R. S. Weinberg (Eds.), Psychological foundations of sport, s.371-386. Champaign, IL: Human Kinetics

Solomon, G.B, Golden, A.J, Ciapponi, T.M. \& Martin, A.D. (1998). Coach expectations and differential feedback: Perceptual flexibility revisited. Journal of Sport Behavior, 21: 298-310

Toros, T. (2010). Turnuva öncesi ve turnuva sonrası basketbolcuların algıladıkları antrenörlük davranışı, görev-ego yönelimli hedefleri, takım saldırganlığı, ustalık-performans iklimi ve kolektif yeterlik arasındaki ilişki. Uluslararası Insan Bilimleri Dergisi, 7(2), 1118-114

Uzun, R.U., Çon, M., Taşmektepligil, M.Y., \& İmamoğlu, O. (2017). Bireysel ve takım sporlarında sporcuların antrenörlerinin kendilerine karşı davranışlarını algılama düzeyi, In The International Balkan Conference in Sport Sciences, abstract book.

Veljkovic, A.A., Djurovic, D., Dimic, I., Mujanovic, R. \& Markovic, K.Z. (2016). College athletes' perceptıons of coachıng behaviours: Differences between individual and team sports, Baltic journal of sport \& health sciences, no. 2(101); 6165 . 
Demiral, Ş. (2019). Gençler Kategorisindeki Judocuların Antrenör Davranışlarını Değerlendirmesi; Saha Çalışması, CBÜ Beden Ĕ̈itimi ve Spor Bilimleri Dergisi, 14 (2), 249-262.

Walling, M. D., Duda, J. L. \& Chi, L., (1993). The perceived motivational climate in sport questionnaire: construct and predicative validity. Journal of Sport and Exercise Psychology, 15, 172-183.

Yapar, A., \& İnce, M. L. (2014). Sporcular için antrenör davranışlarını değerlendirme ölçeğinin Türkçe uyarlaması (Saddö): geçerlik ve güvenirlik çalışması. Spor Bilimleri Dergisi, 25(4), 203-212. 